\title{
O DIREITO AO TRANSPORTE COMO DIREITO FUNDAMENTAL SOCIAL
}

\section{THE RIGTH TO TRANSPORT AS A FUNDAMENTAL SOCIAL RIGHT}

\author{
${ }^{1}$ Roberto Berttoni Cidade \\ ${ }^{2}$ Teófilo Marcelo de Arêa Leão Júnior
}

\begin{abstract}
RESUMO
Promulgada a Emenda Constitucional $n^{\circ} 90$ integrou-se o direito ao transporte no rol dos direitos constitucionais sociais fundantes. O presente artigo, via pesquisa bibliográfica, busca identificar as características dessa fundamentalidade, contextualização histórica de contemporaneidade, os efeitos jurídicos na tentativa de resposta à possível situação de aplicabilidade direta. Pretende-se focar os primordiais pontos da temática utilizando o método hipotético-dedutivo mediante análise interdisciplinar entre o Direito Constitucional, Direito Administrativo e a Filosofia do Direito, na construção do saber jurídico. Justifica-se a pesquisa para possibilitar reflexões do novo direito, direcionado ao desenvolvimento, sem a pretensão de esgotamento da matéria.
\end{abstract}

Palavras-chave: 1 . direito constitucional, 2. direitos sociais, 3. neoconstitucionalismo, 4. direito ao transporte

\begin{abstract}
Enacted Constitutional Amendment No. 90 incorporated the right to transport on the list of founding social constitutional rights. This article, via literature research, seeks to identify the characteristics of fundamentality, historical context of contemporaneity, legal effects in an attempt to answer the possible situation of direct applicability. It's intended to focus on the overarching theme of points using the hypothetical-deductive method through interdisciplinary analysis of the Constitutional Law, Administrative Law and Philosophy of Law, in construction of legal knowledge. It is appropriate to search for possible reflections of the new law, directed to development without depletion of claim of matter.
\end{abstract}

Keywords: 1 . constitutional law, 2. social rights, 3. neoconstitutionalism, 4. right to transport

\footnotetext{
${ }^{1}$ Mestrando em Direito pelo Centro Universitário Euripedes de Marília - UNIVEM, São Paulo (Brasil).

E-mail: advcidade@gmail.com

${ }^{2}$ Doutor em Direito pela Instituição Toledo de Ensino - ITE, São Paulo (Brasil). Professor pelo Centro

Universitário Euripedes de Marília - UNIVEM, São Paulo (Brasil). E-mail: teofilo@arealeao.com
} 


\section{INTRODUÇÃO: as primeiras palavras}

A aprovação e promulgação da Emenda Constitucional n ${ }^{\circ} 90$ positivou expressamente no artigo $6^{\circ}$ da Constituição Federal o direito ao "transporte" na categoria de direito social, ao lado e no mesmo dispositivo constitucional dos direitos à educação, à saúde, o trabalho, o lazer, à segurança, à previdência social, à proteção à maternidade e à infância, à assistência aos desamparados (escolhas do legislador originário), à alimentação, à moradia, estes acrescidos pelo poder reformador de 2000 e 2010, respectivamente.

Embora seja mais uma conquista no mundo jurídico, certo que a inclusão do direito ao transporte no rol dos direitos sociais fundantes, traz questionamentos sobre a aplicabilidade dado o seu caráter aberto; e a sociedade, por meio de seus intérpretes, deve ser chamada a modular o instituto e estabelecer os limites $^{1}$ ou ampliar o seu âmbito normativo, ainda que indiretamente, para aplicabilidade e realização.

Sem a pretensão de esgotamento da matéria, discorre-se sobre dos elementos fundantes do aparente "novo" direito, o impacto dessa constitucionalização no sistema jurídico vigente, eventuais possibilidades de aplicação imediata e impedimentos modais.

Assim, a presente pesquisa é pautada no método de investigação dedutivo, cujos procedimentos técnicos adotados foi bibliográfico e jurisprudencial, como livros, doutrina, leis e julgados. Com efeito, parte-se de um estudo bibliográfico e jurídico, para posterior abordagem do atual contexto legislativo brasileiro mediante a adoção de um ponto de partida constitucional de uma reforma constitucional e seus efeitos.

\section{O DILEMA: FUNDAMENTABILIDADE DO TRANSPORTE COMO DIREITO MEIO OU DIREITO FIM}

Sem a necessidade de extensa explanação para a contextualização de contemporaneidade, destaca-se que a hermenêutica hodierna contempla teorias, dentre elas a teoria nominada neopositivista por uns, e pós-positivista por outros, sendo aquela que possui o elemento central a reaproximação da ética ao direito, no escopo de garantir a máxima efetividade normativa aos institutos voltados à garantia e acesso da dignidade da pessoa humana (BARROSO, 2005, p. 15).

\footnotetext{
1 Opta-se pelo termo "limite", pois, considera os aspectos positivo e negativo da norma vinculante; sendo que o primeiro está ligado àquilo que pode ser razoavelmente exigido ao Estado (Mínimo Existencial) até o limiar de suas reservas financeiras (Reserva do Possível) como limite subjetivo privado, não obstando, porém, sua maior densificação voluntária, o que é desejável; já quanto o segundo aspecto, a fim de garantir a dignidade humana, se trata daquilo que o Estado pode razoavelmente exigir do particular, pautado na essência limitativa constitucionalista.
} 
Juridicamente, esse fenômeno ideológico se caracteriza pela "absorção de valores morais e políticos, fenômeno designado como materialização da Constituição, sobretudo em um sistema de direitos fundamentais autoaplicáveis" insertos no texto Constitucional (MENDES, 2014. p. 62). Ainda, esse movimento doutrinário jurisprudencial é pautado no reconhecimento da força normativa da Constituição, a expansão da jurisdição constitucional e no desenvolvimento de uma nova dogmática da interpretação constitucional (BARROSO, 2005 , p. 6), cujos aspectos serão tratados brevemente conjuntamente ao objeto principal do estudo, sob pena de perda de objetividade.

Desta feita, a constatação da fundamentalidade do direito em comento orienta-se pelos ensinamentos de Robert Alexy, forte em Joaquim José Gomes Canotilho (1993, p.498) e Ingo Wolfgan Sarlet (2008-a. p. 25), este último inspirado nos anteriores e dirige o raciocínio no sentido de que os institutos jurídicos voltados à proteção especial da dignidade da pessoa humana, notadamente naquilo que atualmente se intitula "mínimo existencial", deve servir de elemento norteador das políticas nacionais, com aspiração no constitucionalismo clássico, objetivando os limites e parâmetros dos atos estatais em todas suas instâncias.

O objeto dessa proteção é a própria dignidade, cujo marco histórico foi a Declaração Universal dos Direitos Humanos de 1948, hoje compreendido como princípio jurídico (Artigo $1^{\circ}$, III, Constituição Federal) e, nas palavras de Ingo Wolfgan Sarlet (2008b, p. 7), pode ser entendido como:

[...] qualidade intrínseca e distintiva reconhecida em cada ser humano que o faz merecedor do mesmo respeito e consideração por parte do Estado e da comunidade, implicando, neste sentido, um complexo de direitos e deveres fundamentais que assegurem a pessoa tanto contra todo e qualquer ato de cunho degradante e desumano, como venham a lhe garantir as condições existenciais mínimas para uma vida saudável, além de propiciar e promover sua participação ativa e co-responsável nos destinos da própria existência e da vida em comunhão com os demais seres humanos.

Denota-se, assim, o princípio da dignidade da pessoa humana ser o núcleo das atividades políticas estatais. Sobre isso Carmen Lúcia Antunes Rocha (1999, p. 7) afirma:

Esse princípio vincula e obriga todas as ações e políticas públicas, pois o Estado é tido como meio fundado no fim que é o homem, ao qual se há de respeitar em sua dignidade fundante do sistema constituído (constitucionalizado). É esse acatamento pleno ao princípio que torna legítimas as condutas estatais, as suas ações e as suas opções.

A noção de dignidade tem base no princípio da igualdade, cujo objeto, consoante os ensinamento de Celso Antônio Bandeira de Mello (2000, p. 18), presta-se: 
[...] a impossibilidade de desequiparações fortuitas e injustificadas. Para atingir este bem, este valor absorvido pelo Direito, o sistema normativo concebeu fórmula hábil e interdita, o quanto possível, tais resultados, posto que, exigindo igualdade, assegura que os preceitos genéricos, os abstratos e atos concretos colha a todos sem especificações arbitrárias, assim proveitosas que detrimentos as para os atingidos.

Ao considerar o exercício da cidadania, que tem como pressuposto a vida digna, pode e deve ser amparado por instrumentos jurídicos que, por sua natureza, buscam minorar as desigualdades e carências sociais por serem instrumentos transformadores da realidade, pela sua força normativa, o leva o signo de direitos fundamentais no sistema jurídico.

Em corroboração ao reconhecimento do direito ao transporte como um direito fundamental, forte em Daniel Sarmento (2010. p. 54) que considera "a principal finalidade dos direitos fundamentais é conferir aos indivíduos uma posição jurídica de direito subjetivo, em sua maioria de natureza material, mas às vezes de natureza processual e, consequentemente, limitar a liberdade de atuação dos órgãos do Estado".

Com efeito, relembram Joaquim José Gomes Canotilho (1993, p. 498) que "a positivação jurídico-constitucional não «dissolve» nem «consome» quer o momento de «jusnaturalização» quer as raízes fundamentantes dos direitos fundamentais (dignidade humana, fraternidade, igualdade, liberdade)", mantém-se, portanto, as características de elemento legitimativo-fundamentante da própria ordem jurídico-constitucional.

O mesmo autor identifica, pois, tais normas como possuidoras de Fundamentalidade formal e material (CANOTILHO, 1993, p. 499). No primeiro caso, encontra-se em destaque a hierarquia na ordem jurídica, maior dificuldade no procedimento de sua revisão, é vinculatório e imediato ao Estado. No segundo, é constitutivo das estruturas Estatais de caráter aberto, propiciando a densificação e reconhecimento de novas expressões de tais direitos.

Todas estas características estão contidas no presente caso. Na visão material, o direito ao transporte se trata de direito que garante acesso aos demais direitos sociais (logo, direito meio) e se presta a assegurar o status jurídico material do cidadão, tornando acertada a inserção no rol do artigo $6^{\circ}$ da Constituição Federal, até por ser considerado ${ }^{2}$ como cláusula pétrea em extensão do disposto no $\$ 4^{\circ}$ do artigo 60, do mesmo dispositivo legal.

2 Embora não seja expressamente reconhecido a condição de cláusula pétrea, autores como Ingo Wolfgan Sarlet, Daniel Sarmento, Luís Roberto Barroso, entre outros, atribuem aos direitos sociais o mesmo caráter de fundamentalidade, doutrina qual compactuam-se. Sobre o tema: "a moderna doutrina constitucional, sem desprezar o aspecto didático da classificação tradicional em gerações ou dimensões de direitos, procura justificar a exigibilidade de determinadas prestações e a intangibilidade de direitos pelo poder reformador $n a$ sua 


\title{
2 BREVES ASPECTOS HISTÓRICOS DA MOBILIDADE URBANA
}

O objeto central do direito ao transporte está ligado à mobilidade urbana, tanto que, durante a tramitação do projeto da EC 90, por algumas vezes houve a sugestão de que o "direito social ao transporte" tivesse esse nome. Para melhor compreensão da expressão, Valter Fanini (2011, p. 10) a conceitua:

\begin{abstract}
A mobilidade urbana é um atributo associado às pessoas e atores econômicos no meio urbano que, de diferentes formas, buscam atender e suprir suas necessidades de deslocamento para a realização das atividades cotidianas como: trabalho, educação, saúde, lazer, cultura etc. Para cumprir tal objetivo, os indivíduos podem empregar o seu esforço direto (deslocamento a pé), recorrer a meios de transporte não motorizados (bicicletas, carroças, cavalos) ou motorizados (coletivos e individuais).
\end{abstract}

O que se compatibiliza com o disposto no inciso II, do artigo $4^{\circ}$, da Lei $12.587 / 12$ (Plano Nacional de Mobilidade Urbana):

Art. $4^{\circ}$ Para os fins desta Lei, considera-se: [...]

II - mobilidade urbana: condição em que se realizam os deslocamentos de pessoas e cargas no espaço urbano;

Nota-se, portanto, o direito ao transporte visa garantir o acesso a todos os espaços e equipamentos das cidades, por meio da infraestrutura e modalidades, para que o cidadão usufrua das suas funções urbanas. Isto porque, nas lições de Andreas J. Krell (2002. p. 19) "Os direitos Fundamentais sociais não são direitos contra o Estado, mas sim direitos através do Estado, exigindo do poder público certas prestações materiais". Em outros termos, "tal como observado por Krebs, não se cuida apenas de ter liberdade em relação ao Estado (Freiheit vom...), mas de desfrutar essa liberdade mediante atuação do Estado (Freiheit durch...)" (MENDES, 1999. p.2).

Nessa linha o instituto direciona positivamente o Estado para agir na elaboração de um Sistema de Circulação e Transportes, com articulação intra e interurbana, para que o deslocamento se dê em tempo considerado ideal, razoável, de modo confortável e seguro.

Deve-se frisar que depois da Revolução Industrial houve um fenômeno mundial de inchaço dos meios urbanos, quando as cidades não estavam preparadas para receber esse volume de pessoas, o que ocasionou zonas de conflitos viários impeditivos à plenitude do gozo dos bens da vida suscitados.

essencialidade para assegurar uma vida digna. Com base em tal premissa, não são apenas os direitos individuais que constituem cláusulas pétreas, mas também as demais categorias de direitos constitucionais, na medida em que sejam dotados de fundamentalidade material" (BARROSO, 2005, p. 179). 
Neste sentido, um dos primeiros documentos urbanístico que diagnosticou estes conflitos foi a Carta de Atenas, de $1933^{3}$, que identificou, entre os mais diversos problemas de circulação europeia, a inadequação e ausência de padronização do tamanho das vias à existência de muralhas antigas que outrora protegiam as cidades, e já expunha:

O problema é criado pela impossibilidade de conciliar as velocidades naturais, do pedestre ou do cavalo, com as velocidades mecânicas dos automóveis, bondes, caminhões ou ônibus. Sua mistura é fone de mil conflitos. O pedestre circula em rua insegura perpétua, enquanto os veículos mecânicos, obrigados a frear com frequência, ficam paralisados, o que não os impede de serem um perigo permanente de morte.

Em suma, as vias/ruas antigas, como se mostra, não foram planejadas para receber o volume tráfego, nem tampouco o tipo de já veículo utilizado à época, quanto muito os atuais, o que acabou por gerar riscos aos usuários e dificuldades de mobilidade urbana, ocasionando obstáculos para o acesso de direitos, tal como o trabalho. Voltada para a observação de necessidade de planejamento urbanístico, o mesmo instrumento, rezava que "a circulação tornou-se (...) função primordial da vida urbana", o que não difere da atualidade pela ausência de planejamento/investimento adequados das vias.

Continuando, o fenômeno do êxodo rural e migração aos centros urbanos ocorreu de forma análoga em território nacional na segunda metade do século XX, deixando o país de ser predominantemente rural para majoritariamente urbano. De acordo Valter Fanini (2011, p.10) esta transformação se deu segundo:

[...] um modelo de desenvolvimento urbano excludente e altamente concentrador nos aspectos econômicos, territoriais e demográficos - cerca de $60 \%$ da população urbana brasileira vive hoje em 224 municípios com mais de 100 mil habitantes, dos quais 94 pertencem a aglomerados urbanos e regiões metropolitanas com mais de um milhão de habitantes -, privando as faixas de menor renda das condições básicas de inserção efetiva à cidade e ao meio urbano.

Do diagnóstico supra se extrai algumas observações que dão a tônica do fomento à positivação do direito ao transporte, posto que o "desenvolvimento" excludente da sociedade moderna necessita de medidas efetivas a fim de viabilizar que aquele cidadão que se encontre

3 Carta de Atenas de novembro de 1933 - Assembleia do CIAM - Congresso Internacional de Arquitetura Moderna - 1933. Disponível em: <https://www.google.com.br/url? sa=t\&rct=j\&q=\&esrc=s\&source=web\&cd=2 $\&$ cad=rja\&uact=8\&sqi=2\&ved=0CCEQFjABahUKEwjUndDOi73IAhXJIpAKHSNYB6w\&url=http $\% 3 \mathrm{~A} \% 2 \mathrm{~F} \%$ 2Fportal.iphan.gov.br\%2Fuploads\%2Fckfinder\%2Farquivos\%2FCarta\%2520de\%2520Atenas\%25201933.pdf\& usg=AFQjCNFq9c68dBDHBsPN-1KHrp893BSuBA\&sig2=P076CEHJeyHkbrh98NSMLQ\&bvm=bv.10481942 0,d.Y2I>. Acesso em 12 out. 2015. 
em logradouros mais distantes tenham a possibilidade de acesso a todos os equipamentos e serviços urbanos.

No Brasil, apenas em 2001, por meio do Estatuto das Cidades (Lei n. 10.257/01) que se permitiu maior amplitude de participação popular nas políticas públicas urbanas.

Conjuntamente a isso, a política econômica nacional fomentou da indústria automotiva sem, paralelamente, elaborar um sistema de transporte coletivo compatível; e, o aumento indiscriminado da frota veicular privada provocou o surgimento de congestionamentos infindáveis. A esse respeito:

Nos anos 1960, quando começou a indústria automobilística no Brasil, produzia-se 1.200 automóveis e 2.200 ônibus por ano. Em 2011, a indústria automobilística já produzia por ano 3,5 milhões de automóveis e 40 mil ônibus. Desses 40 mil, apenas 20 mil ficam no Brasil, porque 20 mil são exportados. Da indústria automobilística, certamente esses 3,5 milhões de carros permanecem aqui, mesmo porque há aqueles que são importados. O que aconteceu com a mobilidade urbana no Brasil nesse período? Nos anos $1960,15 \%$ da população se deslocava pelo transporte individual, enquanto $85 \%$ se deslocava pelo transporte público. Agora em 2010, 50\% estão no transporte público e $50 \%$ se deslocam pelo transporte individual. A permanecer essa tendência, em 2030 acho que as cidades estarão paradas com essa curva, produzindo $65 \%$ dos deslocamentos em transporte individual e 35\% no transporte público (CUNHA FILHO, 2013, [s.p.]).

Outros dados relevantes quanto a ausência de investimentos e planejamentos na área de transporte urbano são aqueles obtidos junto ao Perfil dos Municípios Brasileiros 20124 denota a relevância da discussão sobre o tema e necessidade de criação de instrumentos jurídicos sanar as mazelas do Estado com a positivação do direito ao transporte.

Dos 5565 municípios brasileiros, 74,26\% contam com estrutura na área de transporte, por caracterização do órgão gestor (secretarias e afins), no entanto, apenas 3,77\% do total contam com Plano Municipal de Transporte (compreendido como medidas de participação da sociedade civil na elaboração do plano; priorizar o transporte coletivo e as áreas destinadas aos pedestres; apontar diretrizes que fortaleçam a gestão do transporte coletivo; auxiliar ou contribuir para o estabelecimento da política tarifária; estabelecer políticas integradas intermunicipais e outras).

Outrossim, dos municípios que contam com serviços de transporte ${ }^{5}$, tão somente 19 deles $(0,34 \%)$ possuem o serviços de metrô, 139 (2,49\%) o serviços de trem, e $641(11,51 \%)$

4 Disponível em:< http://www.ibge.gov.br/home/estatistica/economia/perfilmunic/2012/defaulttabzip_xls.shtm> Acesso em 09 out. 2015.

5 Dados atualizados em 06/08/2013. 
o serviço de barco, voltando ao ponto de que a imensa maioria da infraestrutura e política pública de transporte se dá pela malha viária terrestres.

Nesse panorama, em que pese $4.645(83,46 \%)$ tenham o serviço de táxi, 3.079 $(55,32 \%)$ o serviço de moto-táxi e 3.767 (67,69\%) o serviço de van, o atendimento majoritário da população em transporte coletivo, dentro da política atual, deveria ser priorizado por meio de ônibus. Porém, apenas 2.114 (37,98\%) municípios oferecem os serviços de ônibus intramunicipal, e 4775 (85,08\%) serviços de ônibus intermunicipal.

Ressalta, ainda, que a realidade dos serviços de transporte de ônibus intramunicipal, quando prestados, em boa parte das cidades, configuram-se aquém do desejado.

Por amostragem, afigura-se a pesquisa do IDEC (Instituto de Defesa do Consumidor) realizada nas regiões metropolitanas de São Paulo e Belo Horizonte no ano de 2013, apresentaram diversos vícios, sendo os mais comuns: a distância até os pontos de ônibus, demora nas linhas, atraso constante, superlotação e deficiência do atendimento junto ao Serviço de Atendimento ao Consumidor - SAC.

Além de todos esses empecilhos, deve se dar relevo à questão da política tarifária. Esta em 2013 foi o estopim para diversas manifestações populares, em especial pelo movimento "tarifa zero", questionando o valor cobrado pelo serviço de má qualidade, até porque “[...] temos 37 milhões de brasileiros excluídos do transporte, porque não podem pagar o preço da passagem, [...]" (CUNHA FILHO, 2013, [s.p.]), fato este muito comentado nas comissões onde tramitou da Emenda Constitucional no 90 do transporte.

Ao analisar este conjunto de dados conclui-se que há evidência de carência no serviço de transporte coletivo, e que a atual política pública viária, na maioria dos municípios, embora possuam formalmente órgão gestor local, não oferecem o serviço de ônibus intramunicipal, mantendo o fomento do transporte individual (carro/moto), perpetuando a deficiência no acesso aos direitos sociais anteriormente positivados.

Ademais, diante das crises econômicas globais, a escassez de recursos ambientais e a produção de poluição, falar-se hoje em mobilidade urbana não faz sentido algum se deixar de considerar o seu aspecto sustentável, consoante previsto no artigo $5^{\circ}$, II da Lei 12.587/12 (Plano Nacional de Mobilidade Urbana), problema que deve ser encarado de forma multidisciplinar. Com efeito:

A Mobilidade Urbana Sustentável pode ser definida como o resultado de um conjunto de políticas de transporte e circulação que visa proporcionar o acesso amplo e democrático ao espaço urbano, através da priorização dos modos não motorizados e coletivos de transporte, de forma efetiva, que não gere segregações espaciais, socialmente inclusiva e ecologicamente 
sustentável. Ou seja: baseado nas pessoas e não nos veículos (FANINI, 2011, p. 10).

Enfim, os elementos acima se prestam a demonstrar a premência da necessidade de discussão das políticas públicas de transporte, com o fomento da participação de gestão popular, notadamente no que concerne ao transporte coletivo, que, em face da positivação desse direito surge a condição de, ao menos em tese, pensar na judiciliazação em caso de omissão estatal em atender aos anseios sociais.

Gregório Peces-Barba Martinez (2009, p. 26) forte em Brestain:

La socialdemocracia no puede ansiar ni confiar em el cercano derumbe del sistema económico existente si lo piensa como el produto de uma espantosa gran crisis comercial. Lo que ella debe hacer, y ésta es uma buena tarea a largo plazo, es organizar políticamente a la classe obrera y formala para la democracia y a lucha em el Estado por todas las reformas conducentes a elevar a la classe obrera y a transformar al Estado em el sentido de la democracia.

Denota-se, que o contexto histórico apresentado pelo autor, teve como foco a luta pela democracia do Estado para elevar a classe obreira. Em paralelo, neste trabalho, busca-se demonstrar que o direito ao transporte, agora constitucionalizado, visa eminentemente transformar o Estado na busca de sua efetivação desse direito e a plena democracia.

\section{DAS COMPETÊNCIAS E LEGISLAÇÃO INFRACONSTITUCIONAL SOBRE AS MATÉRIAS DE TRANSPORTE}

Identificadas as características de fundamentalidade e realizada a contextualização contemporânea do direito ao transporte, passa a relacionar as competências e os instrumentos legais constitucionais e infraconstitucionais que, embora anteriores à Emenda Constitucional $\mathrm{n}^{\circ} 90$ do transporte, materializam substantivamente o referido direito fundamental.

Está previsto no Título VII, Capítulo II, artigos 182 e 183 da Constituição Federal dispositivo que regulamenta a política urbana nacional, com o objetivo de "ordenar o pleno desenvolvimento das funções sociais da cidade e garantir o bem-estar de seus habitantes", incluindo o significado de garantir circulação de pessoas de maneira adequada.

Assim, o texto constitucional, nos termos do artigo 21, XII, “c" a "f”, XX e XXI, atribui à União as seguintes competências:

Art. 22. Compete à União: [...]

XII - explorar, diretamente ou mediante autorização, concessão ou permissão: [...] 
c) a navegação aérea, aeroespacial e a infra-estrutura aeroportuária;

d) os serviços de transporte ferroviário e aquaviário entre portos brasileiros e fronteiras nacionais, ou que transponham os limites de Estado ou Território;

e) os serviços de transporte rodoviário interestadual e internacional de passageiros;

f) os portos marítimos, fluviais e lacustres; [...]

XX - instituir diretrizes para o desenvolvimento urbano, inclusive habitação, saneamento básico e transportes urbanos; [...]

XXI - estabelecer princípios e diretrizes para o sistema nacional de viação;

Por sua vez, o artigo 30 estabelece que compete aos municípios: V - organizar e prestar, diretamente ou sob regime de concessão ou permissão, os serviços públicos de interesse local, incluído o de transporte coletivo, que tem caráter essencial; e, em caráter residual, o artigo $25, \S 1^{\circ}$ do mesmo diploma legal estende a competência ao Distrito Federal, remanescendo a este e aos Estados a capacidade de legislar no que não lhe for vedado.

Para orientar a execução dessa exploração, foi promulgada pela União a Lei $\mathrm{n}^{\circ}$ 12.587/12, que cria a Política Nacional de Mobilidade Urbana, como forma de regulamentar o inciso XX, do artigo 22 e artigo 182 da Constituição Federal, além de atender ao previsto no inciso VII, do art. $2^{\circ}$ e no $\S 2^{\circ}$ do art. 40 da Lei no 10.257/2001 (Estatuto da Cidade), constituindo princípios norteadores do direito ao transporte:

Art. $5^{\circ}$ A Política Nacional de Mobilidade Urbana está fundamentada nos seguintes princípios:

I - acessibilidade universal;

II - desenvolvimento sustentável das cidades, nas dimensões

socioeconômicas e ambientais;

III - equidade no acesso dos cidadãos ao transporte público coletivo;

IV - eficiência, eficácia e efetividade na prestação dos serviços de transporte urbano;

V - gestão democrática e controle social do planejamento e avaliação da Política Nacional de Mobilidade Urbana;

VI - segurança nos deslocamentos das pessoas;

VII - justa distribuição dos benefícios e ônus decorrentes do uso dos diferentes modos e serviços;

VIII - equidade no uso do espaço público de circulação, vias e logradouros; e IX - eficiência, eficácia e efetividade na circulação urbana.

As diretrizes, por sua vez, estão estabelecidas no mesmo dispositivo legal:

Art. $6^{\circ}$ A Política Nacional de Mobilidade Urbana é orientada pelas seguintes diretrizes:

I - integração com a política de desenvolvimento urbano e respectivas políticas setoriais de habitação, saneamento básico, planejamento e gestão do uso do solo no âmbito dos entes federativos;

II - prioridade dos modos de transportes não motorizados sobre os motorizados e dos serviços de transporte público coletivo sobre o transporte individual motorizado; 
III - integração entre os modos e serviços de transporte urbano;

IV - mitigação dos custos ambientais, sociais e econômicos dos deslocamentos de pessoas e cargas na cidade;

$\mathrm{V}$ - incentivo ao desenvolvimento científico-tecnológico e ao uso de energias renováveis e menos poluentes;

VI - priorização de projetos de transporte público coletivo estruturadores do território e indutores do desenvolvimento urbano integrado; e

VII - integração entre as cidades gêmeas localizadas na faixa de fronteira com outros países sobre a linha divisória internacional.

Além dos princípios e diretrizes, o estatuto da cidade traz em seu conteúdo os objetivos e metas a seguir:

Art. $7^{\circ}$ A Política Nacional de Mobilidade Urbana possui os seguintes objetivos:

I - reduzir as desigualdades e promover a inclusão social;

II - promover o acesso aos serviços básicos e equipamentos sociais;

III - proporcionar melhoria nas condições urbanas da população no que se refere à acessibilidade e à mobilidade;

IV - promover o desenvolvimento sustentável com a mitigação dos custos ambientais e socioeconômicos dos deslocamentos de pessoas e cargas nas cidades; e

V - consolidar a gestão democrática como instrumento e garantia da construção contínua do aprimoramento da mobilidade urbana.

Da leitura dos dispositivos poder-se-ia perguntar a finalidade do reconhecimento do direito ao transporte como direito fundamental positivado, vez que a sua "regulamentação" é anterior e já abarca praticamente todo seu âmbito normativo. A resposta está ligada aos limites da ideologia-jurídica de atuação estatal, ou seja, na legitimidade.

Neste ponto, irretocável as proposições de Joaquim José Gomes Canotilho (1999, p. 141), que leciona: “A legitimidade é a legalidade acrescida de sua valoração. É o critério que se busca menos para compreender e aplicar do que para aceitar ou negar a adequação do poder às situações da vida social que ele é chamado a disciplinar”.

Isto é, a positivação do direito ao transporte em norma fundamental constitucional, atribui ao Estado a vinculação de seus atos à verificação dessa legitimidade, tanto na expressão positiva, quanto na expressão negativa, propiciando a eventualidade de reclamação subjetiva em caso de sua inobservância, pois, "normas jurídicas e, ipso fato, normas constitucionais contêm comandos, mandamentos, ordens, dotados de força jurídica, e não apenas moral” (BARROSO, 2009. p. 218).

Quanto a expressão do direito ao transporte, no que se refere a sua regulação infraconstitucional anterior, destaca o Estatuto do Idoso, Lei n. 10.741/2003, prevê em seu artigo 39 a gratuidade de transporte coletivo local. Em seu artigo 40, regulamentado pelo 
Decreto n. 5.934/2006, a gratuidade de duas vagas em transporte coletivo interestadual, ou desconto de no mínimo 50\% em caso de excesso, para idosos de baixa renda; e em seu artigo 41 há expressa disposição da reserva de vagas de estacionamento, além da prioridade de embarque e desembarque no transporte coletivo dispostas no artigo 42.

A Lei do Passe Livre, $n^{\text {o }} 8.899 / 1994$, regulamentada pelo Decreto $n^{\text {o } 3.691 / 2000,}$ concede passe livre às pessoas portadoras de deficiência no sistema de transporte coletivo interestadual. Por sua vez, o recente Estatuto da Pessoa com Deficiência, Lei $n^{\circ}$ 13.146/2015, em seu artigo 46 e seguintes regula o direito à mobilidade com adequações do sistema e frota viárias; e no artigo 53 e seguintes trata da acessibilidade, com o escopo de equalizar as oportunidades àqueles não portadores de limitações.

Nos casos acima, acrescido da situação de gestantes, lactante e pessoas acompanhadas de criança pequena ou de colo, a Lei n. 10.048/2000, prioriza o atendimento.

Para os estudantes, o artigo 208, VII, da Constituição Federal, garante o amplo acesso à educação, o que inclui o serviço de transporte gratuito. Com isso a Lei de Diretrizes e Bases da Educação (Lei 9394/96), com dispositivos acrescidos pela Lei 10.709/03, fixa a obrigação para:

Art. 10. Os Estados incumbir-se-ão de: (...)

VII - assumir o transporte escolar dos alunos da rede estadual. (Incluído pela Lei $\mathrm{n}^{\circ} 10.709$, de 31.7.2003)

Art. 11. Os Municípios incumbir-se-ão de: (...)

VI - assumir o transporte escolar dos alunos da rede municipal. (Incluído pela Lei $n^{\circ} 10.709$, de 31.7.2003)

Com relação ao jovem, aplica-se também o Estatuto da Juventude (Lei n. 12.852/2013), que em seu artigo 32, regulamentado pelo Decreto n. 8.537/2015, concede a gratuidade de duas vagas em transporte coletivo interestadual, ou desconto de no mínimo 50\% em caso de excesso, para aqueles de baixa renda.

Ainda, o paciente que se encontra em Tratamento fora do domicílio ${ }^{6}$, com amparo nos artigos 197 e 198 da Constituição Federal; Lei Orgânica da Saúde nº 8.080/1990, disciplinada pela Portaria Federal no 055/1999 da Secretaria de Assistência à Saúde/Ministério da Saúde, terá suas despesas custeadas pelo Sistema Único de Saúde.

6 O Tratamento fora do domicílio versa sobre direito à paciente do SUS quanto já esgotados os meios de tratamento em seu município; destinado exclusivamente ao paciente atendido na rede pública, ambulatorial e hospitalar, conveniada ou contratada; com possibilidade de agendamento em unidade de referência; inclusive via transporte aéreo, se necessário; pode incluir, se for o caso, as despesas de acompanhante; os critérios de aferição da necessidade são regulamentado pelo Ministério da Saúde; e, em casos de comprovada urgência, enao tenha tempo hábil para o processamento, poderá ser reembolsado, se o paciente possua o processo de TFD autorizado previamente. 
Além disso, há regulamentações regionais/locais que garantem aos estudantes o direito de pagarem meia passagem consoante as competências dos artigos $30, \mathrm{~V}$, e $25, \S 1^{\circ}$, da Constituição Federal. Neste sentido, encontra-se em trâmite o Projeto de Lei 1130/2011, de autoria de Damião Feliciano da Silva - PDT/PB, junto ao congresso para a concessão de meia passagem para estudantes no sistema de transporte coletivo interestadual em âmbito nacional.

Por fim, o trabalhador está afeto a Lei no 7.418/1985, garantindo o direito de percepção do Vale-Transporte para ter acessibilidade ao serviço; e, se não houver transporte público ou outro meio de locomoção o tempo despendido até o local de trabalho, nos termos da Súmula $\mathrm{n}^{\circ} 320$ do TST, obrigatoriamente deve ser computado na jornada de trabalho.

Note-se, portanto, o direito ao transporte não é uma preocupação nova, no entanto, todos os diplomas legais anteriores suscitados carecem de força vinculatória à política nacional de transporte, além de não encontrar identidade às características de fundamentalidade - formal e material -, o que significa que a positivação constitucional fundamental do direito ao transporte traz efetiva alteração no modo de agir dos agentes públicos, que, pela Força Normativa da Constituição impõe a observância das expressões negativa e positiva do instituto, sob pena de caracterização de arbítrio ou omissão.

\section{DOS DIREITOS SOCIAIS, SUA EFICÁCIA, EFETIVIDADE E CARÁTER SUBJETIVO}

Todo direito social é historicamente objetivado e progressivamente introduzido na cultura jurídica, constituindo meio de interpretação, integração e aplicação da ordem jurídica como um todo (CANOTILHO, 1993, p. 171). Pode ser conceituado como uma:

[...] dimensão dos direitos fundamentais do homem, são prestações positivas proporcionadas pelo Estado direita ou indiretamente, enunciadas em normas constitucionais, que possibilitam melhores condições de vida aos mais fracos, direitos que tendem a realizar a regularização de situações sociais desiguais. (SILVA, 2005. p. 287)

Tem como expressão três funções básicas, conforme dispõe Clèmerson Merlin Clève (2003, p. 156) e André Ramos Tavares (2012, p. 122):

(i) Defesa: limitação ao poder público;

(ii) Prestacional: necessitam de atuação positiva do Estado; e

(iii) Injuntiva: reclama regulamentação de equiparação.

O direito de defesa, ligado à dimensão do direito das liberdades civis, versa sobre a possibilidade do cidadão opor-se ao Estado, que, diferentemente dos demais casos, basta que 
este se abstenha de prática de atos ofensivos à dignidade para ver sua eficácia de status negativus atingida.

No aspecto injuntivo, reclama a elaboração de políticas públicas, que podem ser compreendidas como as estratégias e programas governamentais com o escopo de ordenar a disposição dos recursos públicos e coordenar as ações públicas e privadas, no intuito de se atingir objetivos socialmente relevantes e politicamente determinados (BUCCI, 1997. p.91).

Portanto, há de se ressaltar que as escolhas políticas incumbe, ordinariamente, "tanto ao Poder Executivo quanto ao Legislativo a criação das políticas públicas, desde que respeitados os limites do direito financeiro e administrativo, analisando e motivando corretamente a sua formulação, [...]" (FAZO; FALAVINHA, 2010. p. 180), até porque, em observância ao princípio da legalidade estrita administrativa, imperioso se faz a pré-existência de instrumento legal para autorizar a execução que qualquer ato do Estado. O Judiciário, inerte, age se provocado, também pode, a nosso ver suprir as omissões do outro Poder, mesmo que se entenda esse meio como a Judicialização da política.

Ademais, tal qual os demais direitos sociais, o direito ao transporte se trata de norma de caráter aberto, onde "a constituição confere ao legislador uma margem substancial de autonomia na forma e medida em que o direito social de ser assegurado, o chamado "livres espaço de conformação (Ausgestaltungsspielraum)" (KRELL, 2002, p.2), onde o Poder Público não pode se furtar sob pena de configuração de inconstitucionalidade por omissão.

Por fim, o direito ao transporte também é classificado como direito social prestacional, sendo aquele que os serviços ou bens materiais são entregues direta ou indiretamente ao cidadão em consonância a política pública elaborada pelo Estado. E, em caso de não efetividade, cabe ao particular judicializar o seu reclamo.

Neste ponto, destaca que as duas expressões positivas (injuntiva e prestacional), de acordo a doutrina hodierna, não se traduz de mera expectativa, mas sim de efetivo direito subjetivo, pois, “[...] a constituição não é simples ideário. Não é apenas uma expressão de anseios, de aspirações e propósitos. É a transformação de um ideário, é a conversão de anseios e aspirações em regras impositivas, em comandos. Em preceitos obrigatórios para todos: órgãos do Poder e cidadãos" (MELLO, 2011. p. 11).

Em outros termos: "Se o Estado está constitucionalmente obrigado a prover tais demandas, cabe indagar se, e em que medida, as ações com o propósito de satisfazer tais pretensões podem ser juridicizadas, isto é, se, e em que medida, tais ações se deixam vincular juridicamente" (MENDES, 1999. p.2). 
Por oportuno, lembra-se não se trata de tarefa típica a intervenção do Poder Judiciário nas políticas públicas desenvolvidas pelos demais Poderes. Contudo, esta atitude é tolerada "quando haja uma violação evidente e arbitrária, pelo legislador, da incumbência constitucional” (KRELL, 2002. p.185) Cabível, pois, a judicialização em face daqueles legitimados pelas competências para a elaboração e execução das políticas públicas afetas ao direito do transporte, devendo ser considerado, assim, verdadeiro direito subjetivo. "Em outras palavras, a exigibilidade de um direito aparece nas várias fases de organização temporal da política pública, desde o estabelecimento da agenda (agenda setting), a formulação de alternativas, a decisão, a implementação da política, a execução até a fase final, da avaliação" (BUCCI, 2001. p.12), inclusive porque, em se tratando de direitos prestacionais, eles "não se realizam, inteiramente, sem a prévia regulamentação, ou seja, sem a existência de uma política, de um serviço e/ou de uma rubrica orçamentária” (CLÈVE, 2003, p. 157).

Tendo isso em mente, surge diversas questões tais como: $\mathrm{O}$ particular (individualmente ou coletivamente) pode exigir a implementação de uma linha de transporte convencional em seu bairro? Cabível requerer a implementação de um sistema viário de transporte público em um município em que o serviço não é contemplado? Em caso de não preenchimento dos requisitos de acessibilidade normativamente dispostos, possível a responsabilização civil do órgão estatal? Em caso de ausência de interessados de exploração de transporte público local, fica o município obrigado a subsidiá-lo? Considerando o $\S 1^{\circ}$, do artigo $3^{\circ}$ do Decreto n. 5.934/06, e $\S 1^{\circ}$, do artigo 13 do Decreto n. $8.537 / 15$, que possuem a mesma reação ${ }^{7}$, e consideram "transporte convencional” aqueles realizados pelos serviços rodoviários, ferroviário e marítimo, em caso justificado e de premência necessidade não seria justo a realização de sua interpretação analógica para o sistema aéreo com o objetivo de dar efetividade à norma constitucional? Possível a intervenção judicial para a revisão da política tarifária? E quem vai pagar a conta?

Enfim, ao passo que se considera o direito ao transporte um direito subjetivo, todas estas questões são passíveis de serem analisadas pelo Poder Judiciário, à luz do direito da inafastabilidade de sua apreciação, desde que legitimamente provocado (FAZO; FALAVINHA, 2010. p. 183).

$7 \S 1^{\circ}$ Para fins do disposto no caput, incluem-se na condição de serviço convencional:

I - os serviços de transporte rodoviário interestadual convencional de passageiros, prestado com veículo de características básicas, com ou sem sanitários, em linhas regulares;

II - os serviços de transporte ferroviário interestadual de passageiros, em linhas regulares; e

III - os serviços de transporte aquaviário interestadual, abertos ao público, realizados nos rios, lagos, lagoas e baías, que operam linhas regulares, inclusive travessias. 
Porém, a concessão ou não de tais direitos via judicialização depende da verificação de (a) a existência de política pública; (b) a adequação de sua execução; e, a (c) compatibilidade das condicionantes de realidade na relação entre a necessidade para a manutenção da dignidade (mínimo existencial) e disponibilidade de recursos financeiros (reserva do possível). Isto é, conforme Maria Paula Dallari Bucci (2001, p. 9):

[...], apesar de a exequibilidade da Constituição depender de quanto o seu texto corresponde ao equilíbrio real de forças políticas e sociais em determinada momento, não basta uma Constituição bem escrita para que ela seja cumprida e obedecida, há possibilidade de se travar, pelas vias do direito e com base na Constituição, uma batalha própria, capaz de melhorar as condições sociais, por meio da garantia do exercício de direitos individuais e de cidadania a todos, da forma mais abrangente possível. Nesse sentido, uma ordem jurídica bem estabelecida pode ser instrumento significativo de melhoria social.

No caso em testilha, verificou-se anteriormente ao reconhecimento do direito ao transporte como um direito fundamental positivado a existência de uma política pública de mobilidade urbana estabelecida pela Lei n. 12.587/12, qual deve servir como parâmetro às demais polícias regionais e locais, ou supri-las em caso de ausência como base legal para formação do convencimento motivado. Logo, a judicialização de eventual demanda em torno da matéria tem contornos mais definidos que a aplicabilidade imediata e direita do texto constitucional, o que desde já preenche o item "a" acima.

Já a adequação das medidas implica no reconhecimento de conseguir a máxima efetividade, pautando-se pelos princípios da razoabilidade e proporcionalidade, por meio de ponderação, haja vista impossível a concretização imediata integral (horizontalmente), cujo cumprimento marcha progressiva e dependente do ambiente social, da riqueza da sociedade, da eficiência e elasticidade dos mecanismos de exploração. Viável, porém, a intervenção judicial para, ao menos, a manutenção do status quo, em prestígio ao princípio da proibição de retrocesso, tendendo, sempre, à sua densificação, o que contempla o item "b" acima.

Por fim, o item de maior complexidade para a obtenção de consenso é a equalização dos recursos financeiros disponíveis e a necessidade da máxima efetividade. O primeiro ponto que se destacar são os diversos dispositivos legais já suscitados nessa pesquisa que concedem gratuidade ou descontos para cidadãos em situações específicas, pois, a conta fica à cargo de quem? Em primeira análise, a cargo da empresa que explora a atividade, o que desde já põe em discussão a relação de conflito entre o interesse público albergado pelo direito ao transporte e o princípio da iniciativa privada. Ou seja, como forma de efetivar o direito em estudo, o poder público transfere o ônus ao particular, que, para suprir essa diminuição na 
receita tem como medida aumentar o preço das passagens. Enfim, em última análise, quem acaba por arcar com o este encargo é o usuário que paga pelo serviço.

Neste ponto seria muito fácil, e irresponsável, restituir esse ônus aos cofres públicos para subsidiar essa despesa, uma vez que não se tem previsão de onde viria a receita. Mais impostos? Com efeito, fica pendente de maiores deliberações uma forma de dar acesso àqueles 37 milhões de brasileiros excluídos do transporte público que não podem pagar o preço da passagem, sem onerar aqueles que podem. Portanto, em caso de omissão dos Poderes Executivo e Legislativo, e se legitimamente provocado, restará a ao Poder Judiciário a ponderação da relação existente entre o mínimo existencial e da reserva do possível, como também interpretar a Constituição e a lei e não construi-la.

Lembra, o mínimo existencial se trata de construção teórica, que pondera, historicamente, as circunstâncias e as possibilidades da sociedade, da relação entre a disponibilidade financeira e o aspecto cultural daquilo que seria considerado essencial para a uma vida digna. (BARCELLOS, 2011. p. 180). Logo:

O conceito do mínimo existencial, do mínimo necessário e indispensável, do mínimo último, aponta para uma obrigação mínima do poder público, desde logo sindicável, tudo para evitar que o ser humano perca sua condição de humanidade, possibilidade sempre presente quando o cidadão, por falta de emprego, de saúde, de previdência, de educação, de lazer, de assistência, vê confiscados seus desejos, vê combalida sua vontade, vê destruída sua autonomia, resultando num ente perdido no cipoal das contingências, que fica à mercê das forças terríveis do destino (CLÈVE, 2003, p. 157).

Neste sentido, tudo aquilo que estiver albergado dentro do mínimo existencial, estará excluída possibilidade de se suscitar a "[...] indisponibilidade de recursos com o intuito de salvaguardar o núcleo essencial de outro direito fundamental" (SARLET, 2008-a. p. 25).

$\mathrm{Na}$ outra ponta, tem-se a reserva do possível, que, suscintamente, limita o direito do particular em face o Estado para aquilo que razoavelmente pode ser exigido. Doutrina oriunda da Alemanha, estabelece que, uma vez reconhecida a inexistência de recursos financeiros, acrescido ao fato de que há diligência na elaboração e execução de políticas públicas para a efetivação dos direitos sócias, e desde que não colidam o mínimo existencial acima suscitado, desobriga o Estado de assumir encargos insuportáveis em prol do interesse público (aqui compreendido como manutenção do próprio Estado). A esse respeito:

O princípio da reserva do possível somente pode ser considerado aceitável, portanto, para impedir que os governantes, que não podem fazer milagres para multiplicar os peixes e os pães, sejam responsabilizados pelo que não gastaram daquilo que não tinha. No entanto, não é excludente da exigência 
constitucional de acatamento dos direitos fundamentais e do respeito intransigente, para o que se depende não amenas do quanto se gasta, mas como se gastam os recursos públicos, tendo em visa os princípios da ética, Justiça Social e da solidariedade que firmam os pilares do Estado Democrático de Direito abrigados constitucionalmente (ROCHA, 2005. P. 458).

No mesmo sentido:

Em última análise, a aplicação da teoria da reserva do possível implica reconhecer, de um lado, a inexistência de supremacia absoluta dos direitos fundamentais em toda e qualquer situação; de outro, a inexistência da supremacia absoluta do princípio da competência orçamentária do legislador e da competência administrativa (discricionária) do Executivo como óbices à efetivação dos direitos sociais fundamentais. Isso significa que a inexistência efetiva de recursos e ausência de previsão orçamentária são elementos não absolutos a serem levados em conta no processo de ponderação por meio do qual a decisão judicial deve tomar forma (MÂNICA, 2007. p. 185).

Por tudo isso, fica a difícil missão de equalizar, de um lado o interesse social relativo ao reconhecimento da fundamentalidade do direito ao transporte, e de outro a ausência de reservas financeiras para a implementação eficaz de uma política pública integral, a fim de que o direito-meio garanta o acesso aos demais direitos sociais à milhões de pessoas excluídas por não conseguirem exercer a ampla mobilidade urbana.

\section{CONCLUSÃO}

Da pesquisa realizada verificou-se o que o direito ao transporte versa sobre matéria que traz preocupação à sociedade de longa data. Na sociedade moderna os conflitos viários merecem atenção das autoridades públicas para elaboração de execução políticas públicas atinentes a propiciar a efetiva mobilidade urbana.

As dificuldades e conflitos são fruto da ausência de planejamento e investimento urbanístico, tendo em vista que a sociedade civil após a revolução industrial deixou de ser predominantemente rural para majoritariamente urbana, e até hoje os reflexos desse êxodo rural são percebidos nas sociedades modernas.

Nesta seara, foi sendo introduzido paulatinamente como direito meio para o acesso aos demais direitos sociais, via instrumentos normativos próprios como os que garantiram o Vale Transporte, o Passe Livre, gratuidades e descontos à pessoas em situações especiais como forma de equalizar as desigualdades e agora formalmente em âmbito constitucional, garantindo a sua força vinculatória a todos os órgãos estatais, dando-lhe maior carga de efetividade jurídica. E, neste contexto, ao menos em tese, se torna possível a judicialização de 
inúmeras questões antes descobertas pelo manto da norma jurídica acaso se constate a inexistência ou deficiência de políticas públicas afetas à matéria, se houver provocação legítima do Poder Judiciário.

Para tanto, a resolução de eventual conflito há de ser decidido à luz da relação entre os institutos do mínimo existencial e da reserva do possível, mediante ponderação e razoabilidade, em cada caso concreto. No mais, há a incidência direta de norma infraconstitucional que norteia a política pública de mobilidade urbana (Lei n. 12.587/12).

\section{REFERÊNCIAS}

AFFONSO, Nazareno Stanislau. Gratuidades no Transporte Público Urbano pagas pelos Usuários é Injustiça Social. Ponto de Vista. Associação Nacional de Transportes Públicos ANTP. 2013. Disponível em: <http://antp.org.br/website/noticias/ponto-devista/show.asp?npgCode=873F761C-E90D-4C1A-AB46-DE1C33FAF8E0> Acesso em: 30 set. 2015.

BARROSO, Luis Roberto. Curso de direito constitucional contemporâneo: os conceitos fundamentais e a construção do novo modelo. Rio de Janeiro: Saraiva, 2009.

. Neoconstitucionalismo e constitucionalização do Direito. Revista de Direito Administrativo, Rio de Janeiro, v. 240, p. 1-42, 2005.

. A efetividade das normas constitucionais revisitada. Revista de Direito Processual.

Geral de Justiça: Rio de Janeiro: v. 48. p. 60-98, 1995.

BRASIL. Câmara dos Deputados. Comissão Especial destinada à proferir parecer à Emenda à Constotituição n. 90-A, da Sra Luiza Erundina, que "dá nova recação ao art. $6^{\circ}$ da Constotuição Federal, para introduzir o transporte como direito social. Parecer, 19 nov. 2013. Relator: Nilmário Miranda. Disponível em:<www.camara.gov.br/proposicoesWeb/prop_mostrarintegra?codteor=1192490\&filename =PRL+1+PEC09011+\%3D\%3E+PEC+90/2011> Acesso 12 out. 2015.

BUCCI, Maria P. D., Políticas públicas e direito administrativo. Revista de Informação Legislativa. Brasília, 1997, Pp. 89-98.

.et alli. Buscando um Conceito de Políticas Públicas para a Concretização dos Direitos Humanos. In: Direitos humanos e políticas públicas. São Paulo, Pólis, 2001.

CANOTILHO, José Joaquim Gomes. Direito Constitucional. $6^{\text {a }}$ edição revista. Coinbra: Libraria Almedina Coinbra, 1993.

CLÈVE, Clèmerson Merlin. A eficácia dos direitos fundamentais sociais. Crítica Jurídica, Curitiba, v. 22, p. 17-29, 2003. 
COSTA, Teresa Hilda B. S.; LIMA, Rochelly Euzébio de. Questão Urbana e Serviço Social. Revista Conexão Geraes do CRESS-MG no 5/2014. Disponível : < http://cressmg.org.br/publicacoes/Home/Lei/28> Acesso em: 29 set. 2015.

CUNHA FILHO, Otávio Vieira Da. Sessão: 200.3.54.O. Brasília: Câmara Dos Deputados DETAQ. 09.07.2013. Comissão Geral para debate da política tarifária do transporte coletivo municipal de passageiros. Elaboração e execução de políticas públicas de transporte e mobilidade urbana. Disponível em: <http://www.camara.gov.br/internet/sitaqweb/TextoHTML.asp?etapa=3\&nuSessao=200.3.54. O\&nuQuarto $=27 \&$ nuOrador $=2 \&$ nuInsercao $=0 \&$ dtHorarioQuarto $=11: 27 \& \operatorname{sgFaseSessao}=\mathrm{CG}$ $\% 20 \% 20 \% 20 \% 20 \% 20 \% 20 \% 20 \% 20 \&$ Data $=09 / 07 / 2013 \&$ txApelido=OT\%C3\%81VIO\%20VI EIRA\%20DA\%20CUNHA\%20FILHO\&txEtapa=Com\%20reda\%C3\%A7\%C3\%A3o\%20fina 1>. Acesso em: 30 set. 2015.

FANINI, Valter. Mobilidade Urbana. Série de Cadernos Técnicos. Publicações temáticas da Agenda Parlamentar do Conselho Regional de Engenharia, Arquitetura e Agronomia do Paraná - CREA-PR. 2011. Disponível em:< http://www.creapr.org.br/index.php?option=com_phocadownload \&view=category\&download=538: mobilidad e-urbana\&id=37:cadernos-tecnicos. $>$. Acesso em: 08 out. 2015.

FAZOLI, Carlos Eduardo de Freitas; FALAVINHA, Diego Hermínio Stefanutto. Interpretação e fundamentação nas decisões judiciais sobre políticas públicas. Revista Estudos Jurídicos. Franca-SP: Unesp, a. 14, n.1, p. 179-198, 2010.

HÄBERLE, Peter. Hermeneutica Constitucional. A Sociedade aberta dos interpretes da Constituição: Contribuição para a interpretação pluralista e "procedimental" da Constituição. Tradução: Gilmar Ferreira Mendes. Porto Agegre-RS: Sergio Antonio Fabris Editor, 2002.

KRELL, Andréas J. Direitos sociais e controle social no Brasil e na Alemanha. Porto Alegre: Sérgio Antônio Fabris Editor, 2002.

LEÃO JÚNIOR. Teófilo Marcelo de Arêa. Acesso à moradia: sentença por etapas e políticas públicas. Curitiba: Juruá, 2014.

MANICA, Fernando Borges. Teoria da reserva do possível: direitos fundamentais a prestações e a intervenção do Poder Judiciário na implementação de políticas públicas. Revista brasileira de direito público - RBDP. Belo Horizonte: Fórum, a. 5, n. 18, p. 169186, set-jul. 2007.

MARTINEZ, Gregório Peces-Barba. Los derechos sociales: apuntes políticos y jurídicos. In: Cadernos de La Cátedra de Democracia y Derechos Humanos. n. 1. Madrid: Ed. Universidad de Alcalá.

MELLO, Celso Antônio Bandeira de. Eficácia das normas constitucionais e direitos sociais. 1 ed., $3^{\mathrm{a}}$ tiragem. São Paulo; Malheiros Editores, 2011.

2000

O Conteúdo jurídico do princípio da igualdade. $3^{\text {a }}$ ed. São Paulo: Malheiros, 
MENDES, Gilmar Ferreira; BRANCO, P. G. G.. Curso de Direito Constitucional. 9. ed. São Paulo: Saraiva, 2014.

OLIVEIRA JUMIOR, João Alencar de. Direito à mobilidade urbana: a construção de um direito social. Revista dos Transportes Públicos - ANTP - Ano 33 - 2011 - $1^{\circ}$ quadrimestre. Disponível em: <http://www.antp.org.br/_5dotSystem/download/dcmDocument/2013/01/10/F74345091AFA-478A-9ECD-9D0C9224E3A3.pdf.> . Acesso em: 29 set. 2015.

ROCHA, Carmen Lúcia Antunes. O mínimo existencial e o princípio da reserva do possível. Revista Latino-americana de Estudos Constitucionais. Belo Horizonte: Del Rey, 2005. p. 439-461.

O princípio da dignidade da pessoa humana e a exclusão social. Revista Interesse Público, n.4, 1999, p. 23-49, 1999.

SARLET, Ingo Wolfgang. Direito fundamental ao transporte traz novos desafios a velhos problemas. Revista Consultor Jurídico. 2015. Disponível : $<$ http://www.conjur.com.br/2015-set-25/direitos-fundamentais-direito-fundamentaltransporte-traz-novos-desa> Acesso em: 29 set. 2015.

Os Direitos Sociais como Direitos Fundamentais: contributo para um balanço aos vinte anos da Constituição Federal de 1988. Revista do Instituto de Hermenêutica Jurídica, 2008 .

Disponível em: $<$ http://www.stf.jus.br/portal/cms/verTexto.asp?servico=processoAudienciaPublicaSaude \&pagina=Artigos $>$ Acesso em 12 out.2015.(a)

. Proibição de Retrocesso, Dignidade da Pessoa Humana e Direitos Sociais: manifestação de um constitucionalismo dirigente possível. Revista Eletrônica sobre a Reforma do Estado (RERE), Salvador, Instituto Brasileiro de Direito Público, $\mathrm{n}^{\mathbf{o}}$. 15, setembro/ outubro/ novembro, 2008. Disponível: < ht tp: / /www.direitodoestado.com.br/ rere.asp> . Acesso 29 jan. 2015. (b)

SARMENTO, Daniel. Por Um Constitucionalismo Inclusivo: História Constitucional Brasileira. Teoria da Constituição e Direitos Fundamentais - Rio de Janeiro: Lumen Juris, 2010.

SILVA, José Afonso da. Curso de Direito Constitucional Positivo. 25 ed. São Paulo: Malheiros Editores, 2005.

TAVARES, André Ramos. Curso de direito constitucional. $10^{\circ}$ ed. São Paulo: Saraiva, 2012.

TRANSPORTE PÚBLICO, INSATISTAÇÃO. Revista IDEC: São Paulo, set. 2013. Disponível em: < http://www.idec.org.br/em-acao/revista/a-espera-dequalidade/materia/transporte-publico-insatisfaco-coletiva/pagina/567> Acesso em: 29 set. 2015. 